\title{
Observation of Autohemorrhage as a Defensive Behavior of Natrix natrix (L., 1758) and Natrix tessellata (Laurenti, 1768) from Turkey
}

\author{
Naşit İĞCİ1,2, , Bayram GÖÇMEN³, Mert KARIŞ3, Bahadır AKMAN 4 \\ ${ }^{1}$ Nevşehir Hacı Bektaş Veli Üniversitesi Fen-Edebiyat Fakültesi Moleküler Biyoloji ve Genetik Bölümü, Nevşehir, Türkiye \\ ${ }^{2}$ Nevşehir Hacı Bektaş Veli Üniversitesi Bilim ve Teknoloji Uygulama ve Araştırma Merkezi, Nevşehir, Türkiye \\ ${ }^{3}$ Ege Üniversitesi Fen Fakültesi Biyoloji Bölümü Zooloji Anabilim Dalı, Izmir, Türkiye \\ ${ }^{4}$ Çınar Mühendislik Müşavirlik A.Ş., Ankara, Türkiye
}

\begin{tabular}{l} 
Received: 02.12.2017 Accepted: 22.12.2017 $\quad$ Available online: 26.12.2017 \\
\hline Abstract: We observed autohemorrhage as part of a death feigning defensive behavior of Nartix tessellata in Muradiye, Van \\
(Eastern Anatolian Region, Turkey) and N. natrix in Enez, Edirne (Thrace Region, Turkey) during our herpetological \\
excursions. It is the first record in the literature of this behavior for these snakes in Turkey. We report our observation with \\
photographs and details in this paper.
\end{tabular}

Keywords: Death feigning, dice snake, grass snake, reptilia

\section{Türkiye'den Natrix natrix (L., 1758) ve Natrix tessellata (Laurenti, 1786) Türlerinde Savunma Davranışı Olarak Otohemoraji Gözlemi}

\begin{abstract}
Özet: Yaptığımız arazi çalışmaları esnasında, Muradiye, Van'da (Doğu Anadolu Bölgesi, Türkiye) bulunan bir Natrix tessellato ve Enez, Edirne'de (Trakya Bölgesi, Türkiye) bir N. natrix bireyinde ölü taklidi savunma davranışının bir parçası olarak otohemoraji gözlenmiştir. Adı geçen iki türün bu davranışının gözlemi literatürde Türkiye'den ilk kez kaydedilmiş olup, bu makalede gözlemlere ait detaylar ve fotoğraflar sunulmuştur.
\end{abstract}

Anahtar kelimeler: Ölü taklidi, su yılanı, yarı sucul yılan, reptilia

Yılanlar, diğer sürüngenler, amfibiler ve diğer hayvan gruplarında da olduğu gibi avcılardan korunma amaçlı olarak çeşitli savunma davranışları geliştirmişlerdir (Halliday ve Adler 2004, Budak ve Göçmen 2008). Bu savunma davranışlarının temel amacı av olmaktan kaçmaktır. Etkili bir savunma ve avlanma aracı olarak zehir salgılayan yılanların dahi bir tehditle karşılaştıklarında genellikle ilk hedefleri fark edilmemek ve kaçmaktır. Bu anlamda yılanlardaki başlıca savunma stratejileri mimikri ve kamuflajdır. Bunların yanında şişerek veya vücudunu yassılaştırarak kendini olduğundan büyük gösterme ve ses çıararak uyarma gibi davranışlar da görülür. Yılanlar tehdit karşısında fark edilmeme noktasında başarılı olamadiklarında, av olmaktan kurtulmak için daha farklı stratejilere de başvurmaktadırlar. Bu stratejilerin en yaygın olanlarından birisi de ölü taklididir. Ölü taklidi davranışı genel olarak amfibiler ve sürüngenler arasında yaygın olan bir savunma davranışıdır ancak bazı türler bu konuda uzmanlaşmıştır. Yılanlarda Leptotyphlopidae, Colubridae (s. l.) ve Elapidae gibi farklı ailelerde ölü taklidi görülmektedir (Gehlbach 1970, Greene 1997, Zug ve Ernst 2004, Halliday ve Adler 2004, Gerald 2008). Bu davranışta genellikle yılan ters döner, ağzını açarak dilini dışarı çıkarır ve kloak bezi salgısıyla kötü bir koku üreterek hareketsiz bir şekilde kalır. Bazı yılanlar ölü taklidini daha da ileri götürerek ağızlarındaki damarlardan kan sızmasını sağlarlar (Gehlbach 1970). Bu olay yalancı kanama veya otohemoraji olarak isimlendirilmektedir. Bazı yılan türlerinin (ör: Tropidophis sp.) de rahatsız edildiklerinde gözlerinden kan sızdırdığ 1 veya fışkırttığ bilinmektedir. Yine Heterodon cinsi yılanlar da ölü taklidi konusunda uzmanlaşmış olup, rahatsız edildiklerinde ters dönüp dillerini dışarı çıkarırlar, midelerindeki besinleri kusarlar ve otohemoraji davranışı da sergileyebilirler (Zug ve Ernst 2004). Boidae ailesine dahil Candoia aspera türünde de otohemoraji savunma davranışı rapor edilmiştir (Bustard 1969). Görüldüğü gibi bu davranış farklı gruplara dahil yılan türlerinde gözlenmektedir. Yılanlar dışında bazı kertenkele türleri ve böcekler gibi diğer bazı hayvan gruplarında da kan/hemolenf sızdırma ve fışkırtma gibi savunma davranışları görülebilmektedir (Moore ve Williams 1990, Halliday ve Adler 2004, Bateman ve Fleming 2009).

Natrix natrix ve $N$. tessellata sucul yllan türleridir ve dünya üzerinde geniş bir alanda dağılış göstermektedirler. N. tessellata, Avrupa'dan Misır'ın kuzeyine ve Çin'in kuzeybatısına kadar dağılış göstermektedir (Gruschwitz ve ark. 1999). Türkiye'de ise uygun habitat olan hemen her bölgede bulunmaktadır ve ayrıca Kuzey Kıbrıs Türk Cumhuriyeti'nde de dağılışı vardır (Budak ve Göçmen 2008, Göçmen ve ark. 2008). N. natrix ise, kuzey Afrika ve Iber Yarımadası'ndan Avrupa ve Asya'ya kadar olan yayılışı ile Palearktik bölgenin en geniş yayılışa sahip olan yılanlarından biridir (Kindler ve ark. 2013). Türkiye'de uygun habitat olan hemen her bölgede bulunmaktadır ve ayrıca Kuzey Kıbrıs Türk Cumhuriyeti'nde de dağılış göstermektedir (Budak ve Göçmen 2008, Göçmen ve ark. 2009).

Natrix natrix ve $N$. tessellata ölü taklidi konusunda uzmanlaşmış iki türdür (Ushakov 2007, Budak ve Göçmen 2008, Amr ve Disi 2011). Bu iki tür yakalandıklarını ve köşeye sıkıştıklarını anladıkları anda vücutlarının karın kısmını döndürürler, başlarını yan bir şekilde tutarlar ve dillerini dışarı çıkararak ölü görünümü sergilerler. Kloak 
bezlerinden çıkardıkları pis kokulu salgı ile de ölü taklidi davranısını tamamlarlar ve tehlike geçene kadar hareketsiz bir şekilde kalırlar. Böylece avcılarına ölü ve bozuşmuş izlenimi verirler (Budak ve Göçmen 2008).

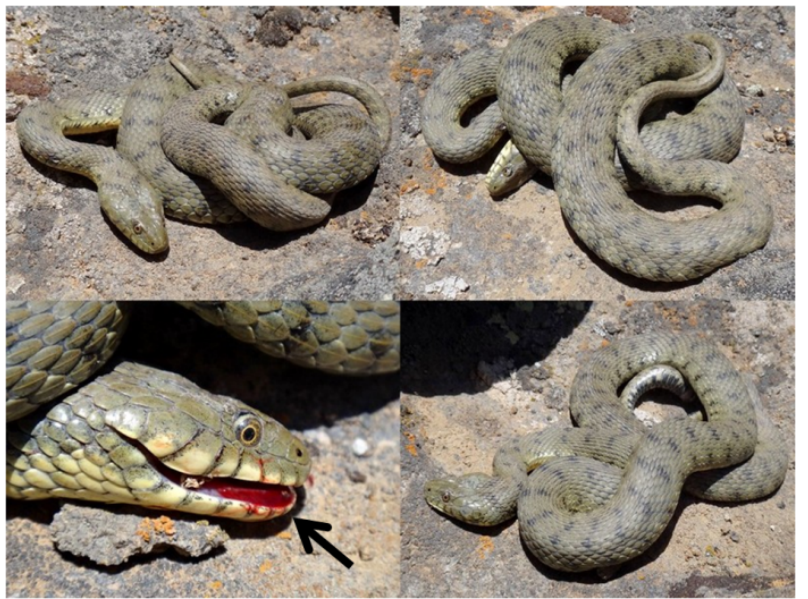

Şekil 1: Muradiye (Van)'de bulunan Natrix tessellata bireyinde ölü taklidi ve otohemoraji davranışı (Fotoğraflar: B. GÖÇMEN)

Şimdiye kadar yaptığımız arazi çalışmalarında çok sayıda $N$. natrix ve $N$. tessellata bireyi gözlemlenmiştir ve tüm bireylerin ilk davranışı kaçma yönünde olmuştur. Fotoğraf çekimi amacıyla yakalandıklarında ısırarak uzaklaştırma davranışı hiçbir bireyde görülmemiştir. Ancak kaçamayacaklarını anladıklarında hemen yukarıda tarif edildiği şekilde ölü taklidi davranışı sergilemektedirler. İki türün ölü taklidi davranışı birbirine oldukça benzemektedir. Yaptı̆̆ımız arazi çalışmaları esnasında, 26.05.2012 tarihinde Muradiye, Van'da erişkin bir N. tessellata bireyinde (Şekil 1) ve 01.05.2017 tarihinde Enez, Edirne'de erişkin bir N. natrix bireyinde (Şekil 2) ölü taklidi esnasında ağız bölgesinden kan sızdırarak otohemoraji davranışı sergilediği görülmüştür ve bu davranışlar fotoğraflanarak kayıt altına alınmıştır. Yılanlar yakalanırken hiçbir zarar verilmemiştir ve ölü taklidine başlamadan önce yılanların ağız bölgesinde herhangi bir kanama veya yara görülmemiştir. Otohemoraji davranışı, yılanların yukarıda bahsedilen tipik ölü taklidine başlamasından 5-10 sn sonra gözlemlenmiştir. İki yılanda da ölü taklidinin başlangıcında önce vücudunun bir kısmını ters döndürerek başını yan çevirme, kötü koku çıkarma ve hareketsiz kalma davranışı görülmüştür.

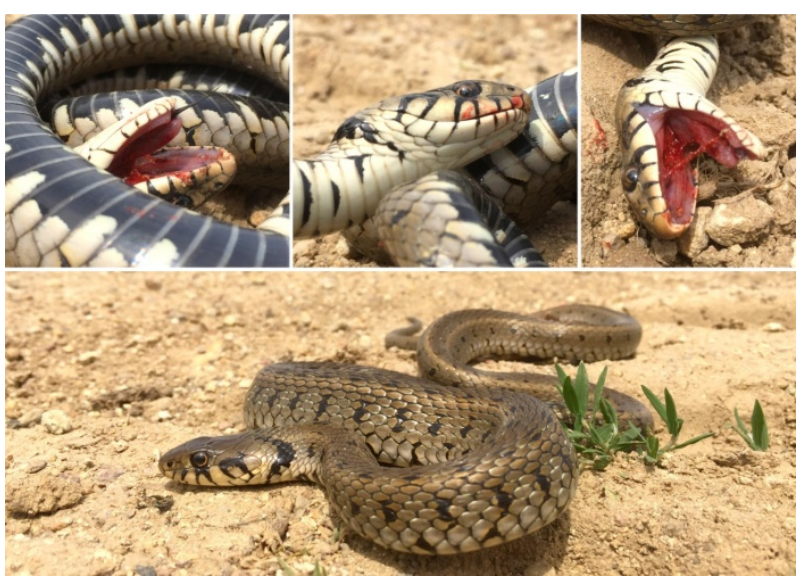

Sekil 2: Enez (Edirne)'de bulunan Natrix natrix bireyinde ölü taklidi ve otohemoraji davranışı (Fotoğraflar: B. GÖÇMEN)

Tipik ölü taklidi davranışı (vücudu ters çevirme, ağzı açarak dili dışarı çıkarma, kötü koku çıkarma ve hareketsiz kalma) çeşitli yılan türlerinde görülmesine rağmen, bu stratejinin bir parçası olarak kullanıldığı düşünülen otohemoraji davranışı daha nadir olarak gözlemlenmektedir. Sayısı az olmakla birlikte şimdiye kadar farklı bölgelerden (ör: İran, Ürdün, İsviçre) $N$. tessellata'da otohemoraji davranışı gözlemleri yapılmıştır ve kayıt altına alınmıştır (Mebert 2007, Amr ve Disi 2011, Rajabizadeh ve ark. 2011). Nadir olmakla birlikte N. natrix türünde de otohemoraji davranışı rapor edilmiştir (Ushakov 2007). Bu kayıtlar değerlendirildiğinde, otohemoraji davranışının bu iki tür için belirli bir popülasyona özgü olmadığı görülmektedir. Bu makale ile Türkiye'de $N$. natrix ve $N$. tessellata türlerinde otohemoraji davranışının gözlemi ilk kez kayıt altına alınmıştır.

Teşekkür: Bu çalışma kısmen Türkiye Bilimsel ve Teknolojik Araştırma Kurumu (TÜBİTAK) tarafından desteklenmiştir (Proje no: 111T338). Saha çalışmalarına katılan Kaan YILMAZ'a (Ege Üniversitesi Fen Fakültesi Biyoloji Bölümü) teşekkür ederiz.

\section{Kaynaklar}

Amr, Z. S., Disi, A. M. 2011: Systematics, distribution and ecology of the snakes of Jordan. Vertebrate Zoology, 61 (2): 179-266.

Bateman, P. W., Fleming, P. A. 2009: There will be blood: autohaemorrhage behaviour as part of the defence repertoire of an insect. Journal of Zoology, 278 (4): 342-348

Budak, A., Göçmen, B. 2008: Herpetoloji. Ege Üniversitesi Fen Fakültesi Yayınları, İzmir, Türkiye.

Bustard, H. R. 1969: Defensive behavior and locomotion of the Pacific Boa Candoia aspera, with a brief review of head concealment in snakes. Herpetologica, 25 (3): 164-170.

Zug, G. R., Ernst, C. H. 2004: Snakes: Smitshonian Answer Book (2nd ed.). Smithsonian Institution Press, Washington and London.

Gehlbach, F. R. 1970: Death-feigning and erratic behavior in Leptotyphlopid, Colubrid and Elapid snakes. Herpetologica, 26 (1): 2434.

Gerald, G. W. 2008: Feign versus flight: influences of temperature, body size and locomotor abilities on death feigning in neonate snakes. Animal Behaviour, 75: 647-654

Göçmen, B., Kaşot, N., Yıldız, M. Z., Sas, I., Akman, B., Yalçınkaya, D. Gücel, S. 2008: Results of the herpetological trips to Northern Cyprus. North-Western Journal of Zoology, 4 (1): 139-149.

Göçmen, B., Atatür, M. K., Budak, A., Bahar, H., Yildiz, M. Z., AlpagutKeskin, N. 2009: Taxonomic notes on the snakes of Northern Cyprus, with observations on their morphologies and ecologies. Animal Biology, 59, 1-30.

Greene, H. W. 1997: Snakes: The Evolution of Mystery in Nature. University of California Press, USA.

Gruschwitz, M., Lenz, S., Mebert, K., Laňka, V. 1999: Natrix tessellate (Laurenti, 1768) - Würfelnatter. In: Böhme, W. (Ed.) Handbuch der Reptilien und Amphibien Europas, Vol. 3/Schlangen II. AULA-Verlag, Wiesbaden, Germany. pp. 581-644.

Halliday, T., Adler, K. 2004: The New Encyclopedia of Reptiles and Amphibians. Oxford University Press, Oxford, UK.

Kindler, C., Böhme, W., Corti, C., Gvoždík, V., Jablonski, D., Jandzik, D., Metallinou, M., Šroký, P., Fritz, U. 2013: Mitochondrial phylogeography, contact zones and taxonomy of grass snakes (Natrix natrix, N. megalocephala). Zoologica Scripta, 42 (5): 458-472.

Mebert, K. 2007: Die Würfelnatter am Brienzersee. UTB Publications, Thun, Switzerland.

Moore, K. A., Williams, D. D. 1990: Novel strategies in the complex defense repertoire of a stonefly (Pteronarcys dorsata) nymph. OIKOS, 57: 49-56.

Rajabizadeh, M., Javanmardi, S., Rastegar-Pouyani, N., Karamiani, R., Yousefi, M., Salehi, H., Joger, U., Mebert, K., Esmaeili, H., Parsa, H., Kami, H. G., Rastegar-Pouyani, E. 2011: Geographic variation, distribution, and habitat of Natrix tessellata in Iran. Mertensiella, 18: 398413

Ushakov, M. V. 2007: On the defensive behavior of the Grass Snake Natrix natrix (Linnaeus, 1758). Russian Journal of Ecology, 38 (2): 124-127. 